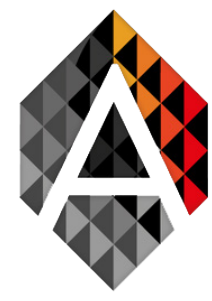

ADCAIJ: Advances in Distributed Computing and Artificial Intelligence Journal

Regular Issue, Vol. 9 N. 4 (2020), 83-94

eISSN: 2255-2863

DOI: https://doi.org/10.14201/ADCAIJ2020948394

\title{
F.A.I.R. open dataset of brushed DC motor faults for testing of AI algorithms
}

\author{
Anibal Reñones ${ }^{\mathrm{a}}$ and Marta Galende ${ }^{\mathrm{a}}$ \\ a Fundación CARTIF, Industry 4.0 area, Parque tecnológico de Boecillo, parcela 206, \\ 47151, Boecillo, Valladolid, Spain \\ aniren@cartif.es, margal@cartif.es
}

\section{KEYWORD ABSTRACT}

Open data;

Artificial

intelligence;

Fault diagnosis;

Predictive

maintenance;

DC motor.
Practical research in AI often lacks of available and reliable datasets so the practitioners can try different algorithms. The field of predictive maintenance is particularly challenging in this aspect as many researchers don't have access to full-size industrial equipment or there is not available datasets representing a rich information content in different evolutions of faults. In this paper, it is presented a dataset with evolution of typical faults (commutator, winding and brush wear) in inexpensive DC motors under extensive monitoring (vibration, temperature, voltage, current and noise). These motors exhibit a particularly short useful life when operating out of nominal conditions (from 30 minutes to 6 hours) which make them very interesting to test different signal processing algorithms and introduce students and researchers into signal processing, fault detection and predictive maintenance. The paper explains in detail the experimentation and the structure of the real, un-processed, dataset published in the AI4EU platform with the aim of complying with the FAIR principle so the dataset is Findable, Accessible, Interoperable and Reusable.

\section{Introduction}

\subsection{Predictive maintenance}

Industrial maintenance represents between $15 \%$ and $70 \%$ of the operational costs of a factory (Bevilacqua et al., 2012), depending on the sector. Preventive maintenance represents the main way to avoid the degradation of productive means, however, human errors, such as erroneous or unnecessary

Anibal Reñones and Marta Galende F.A.I.R. open dataset of brushed DC motor faults for testing of $\mathrm{Al}$ algorithms
ADCAIJ: Advances in Distributed Computing and Artificial Intelligence Journal Regular Issue, Vol. 9 N. 4 (2020), 83-94 eISSN: 2255-2863 - https://adcaij.usal.es Ediciones Universidad de Salamanca - CC BY-NC-ND 
maintenance operations, contribute to $75 \%$ of failures during the life of an equipment (Venkatraman, 2012). Predictive maintenance aims to mitigate these effects through an analysis of the different sources of information available in the workshop and factory offices. The positive impacts of predictive maintenance are numerous, but with variability depending on the sector and actual starting level of reliability of the monitored machines. Such benefits can be a reduction in total costs (related to failure + production losses + maintenance) by $15-30 \%$ or reduction of preventive costs by $10-20 \%$ (IoT, 2017).

Another main beneficial effect of predictive maintenance is that proper analytics of signals and information belonging to the machine's environment provides clues to which machine's component is degrading or have failed. This is called the fault diagnosis and helps reduce the uncertainty in the most appropriate maintenance action. A classic example is the measurement of vibrations that allows to differentiate a failure of an electric motor that has an excess of vibration due to an incipient short circuit or due to a damaged bearing (Liu et al, 2010).

In practice, the implementation of predictive maintenance in a machine or production process is a complex process linked to the complexity of the machine or production process itself. This process can be divided into 4 fundamental stages (Patton et al, 1995):

- Reliability analysis to distinguish those machine components most susceptible to failure.

- Signals selection and measurement of the optimal variables that provide information on the operating status of less reliable components.

- Processing and diagnosis through the analytics of the measured values to generate one or more mathematical indices of the health status of the components.

- Prediction of useful life through an estimation using a mathematical model (e.g. AI based) of the number of hours of operation prior to the failure of the monitored components.

The common denominator of these four stages is the need of available data to advance consecutively in the different procedures. This data need is especially critical when applying artificial intelligence techniques to classify or predict the appearance and evolution of faults. Practical research in AI often lacks available and reliable datasets so the practitioners can try different algorithms (Yanking et al, 2019). The field of predictive maintenance is particularly challenging in this aspect as many researchers do not have access to full-size industrial equipment or there are not available datasets representing a rich information content in different evolutions of faults (Nazmus, 2018). In addition to that, the available datasets are clearly unbalanced as the norm for machines is that they operate properly and only few examples of faults appear during their lifetime.

It's very important from the AI research point of view the availability of reliable and interesting data sources to test different signal processing algorithms and introduce students and researchers into practical application such as signal processing, fault detection and predictive maintenance. Besides, from the governmental point of view European Commission, both European Data Strategy (European Commission, 2020a) and European Data Governance policy (European Commission, 2020b) are powerful initiatives focus on the implementation of European data spaces, among which the Commission proposes the creation of a specific European industrial (manufacturing) data space to take advantages of the strong European industrial base and improve their competitiveness.

Anibal Reñones and Marta Galende F.A.I.R. open dataset of brushed DC motor faults for testing of $\mathrm{Al}$ algorithms
ADCAIJ: Advances in Distributed Computing and Artificial Intelligence Journal Regular Issue, Vol. 9 N. 4 (2020), 83-94 eISSN: 2255-2863 - https://adcaij.usal.es Ediciones Universidad de Salamanca - CC BY-NC-ND 


\subsection{F.A.I.R principles and European initiatives on open data}

The data and other digital objects created by and for researchers need to be findable, accessible, interoperable and reusable (FAIR). These F.A.I.R. principles will boost the digital revolution, to accelerate research, the power of artificial intelligence while guaranteeing transparency, reproducibility and societal utility (European Commission, 2018).

The FAIR guiding principles are the following (Wilkinson, 2016):

\section{To be Findable:}

F1. (meta)data are assigned a globally unique and persistent identifier.

F2. data are described with rich metadata (defined by R1 below).

F3. metadata clearly and explicitly include the identifier of the data it describes.

F4. (meta)data are registered or indexed in a searchable resource.

\section{To be Accessible:}

A1. (meta)data are retrievable by their identifier using a standardized communications protocol.

A1.1 the protocol is open, free, and universally implementable.

A1.2 the protocol allows for an authentication and authorization procedure, where necessary.

A2. metadata are accessible, even when the data are no longer available.

\section{To be Interoperable:}

I1. (meta)data use a formal, accessible, shared, and broadly applicable language for knowledge representation.

I2. (meta)data use vocabularies that follow FAIR principles.

I3. (meta)data include qualified references to other (meta)data.

\section{To be Reusable:}

R1. meta(data) are richly described with a plurality of accurate and relevant attributes.

R1.1. (meta)data are released with a clear and accessible data usage license.

R1.2. (meta)data are associated with detailed provenance.

R1.3. (meta)data meet domain-relevant community standards.

From the governmental point of view European Commission is launching the Open Research Europe (European Commission, 2020c), a scientific publishing service, for Horizon 2020 and Horizon Europe beneficiaries with a service to publish their results in full compliance with commission open access policies. The service will provide an easy, high quality peer-reviewed venue to publish their results in open access, at no cost to them. In addition to the publishing guidelines, data guidelines are also available which adheres the F.A.I.R principles too and refers a number of trusted repositories (European Commission, 2020d).

\subsection{AI4EU project}

AI4EU project ("A European Artificial Intelligence on demand platform and Ecosystem") aims to make available to users resources based on Artificial Intelligence (AI) that facilitates scientific research and innovation, analyses future research needs in AI and creates an observatory of ethics that ensures an $\mathrm{AI}$ focused on human being.

1 This project has received funding from the European Union's Horizon 2020 research and innovation programme under grant agreement No 825619.

Anibal Reñones and Marta Galende F.A.I.R. open dataset of brushed DC motor faults for testing of Al algorithms
ADCAIJ: Advances in Distributed Computing and Artificial Intelligence Journal Regular Issue, Vol. 9 N. 4 (2020), 83-94 eISSN: 2255-2863 - https://adcaij.usal.es Ediciones Universidad de Salamanca - CC BY-NC-ND 
With that situation in mind, the AI for Europe project (AI4EU in short) launched a platform to bring AI stakeholders and AI resources together in one dedicated place (www.ai4eu.es), so AI-based innovations (research, products, solutions) are accelerated. Specifically, the catalogue of AI resources serves as market place where users can navigate and test AI resources to integrate them in their research and develop projects. Before publication, all AI resources (datasets, algorithms, etc...) have to be reviewed and qualified within an own publication process, ensuring the quality of the resources.

With the objective to give visibility to our predictive maintenance dataset, this resource has been subjected to the review process and will soon be available for use by the whole community of IA at https://www.ai4eu.eu/resource/opendcmotor.

\subsection{AI-REGIO project}

AI REGIO project ${ }^{2}$ ("Regions and DIHs alliance for AI-driven digital transformation of European Manufacturing SMEs") aims at supporting AI-driven Digital Transformation of European Manufacturing SMEs, by up-scaling and coordinating different regional smart specialization strategies. The project aims integrating DMPs (Digital Manufacturing Platforms) and DIHs (Digital Innovation Hubs) at a service of cross-border large scale experimentations and by enriching I4MS (Innovation for Manufacturing SMEs) previous results in the domain of Industry 4.0 with innovative AI applications and open platforms.

One of the expected results of the project is the integration of "Data4AI" Open Source Platforms with DIH Innovation Collaboration platform and with multiple technological assets in an AI4Manufacturing" Toolkit, so, in the near future, our predictive maintenance dataset will be also available thought this new platform.

\section{Material and Methods}

The objective was to have access to a system easily tested with also the ability to be reproducible. DC motors are a good example as they can be virtually found in many different applications (Herman, 2010) and there is an extensive portfolio of such electromechanical devices in the market of different sizes and power for a number of applications.

The direct current motor, also called DC motor is a machine that converts electrical energy into mechanical energy, causing a rotary movement, thanks to the action of a magnetic field. A DC motor is mainly composed of three components (for brushed motors):

- The stator gives mechanical support to the device and contains the poles of the machine, which can be either copper wire windings on an iron core, or permanent magnets.

- The rotor is generally cylindrical in shape, also wound and with a core, fed with direct current through the collector formed by thin strips. The blades are generally made of copper and are in alternating contact with the fixed brushes.

- The brushes of low power motors are made of graphite. For those that require high currents, such as vehicle starters, they are made from an alloy of graphite and metal (Fang et al, 2005).

2 This project has received funding from the European Union's Horizon 2020 research and innovation programme under grant agreement No 952003

Anibal Reñones and Marta Galende F.A.I.R. open dataset of brushed DC motor faults for testing of Al algorithms
ADCAIJ: Advances in Distributed Computing and Artificial Intelligence Journal Regular Issue, Vol. 9 N. 4 (2020), 83-94 eISSN: 2255-2863 - https://adcaij.usal.es Ediciones Universidad de Salamanca - CC BY-NC-ND 


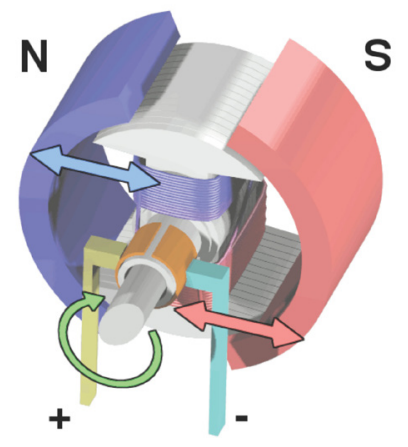

Figure 1 Schematic view of main components of a brushed electric motor with a two-pole rotor (armature) and permanent magnet stator (with polarities $N$ and $S$ ) (Wapcaplet, 2020).

The anatomy of a brushed DC motor includes different elements as seen in the figure bellow (Sparkfun, 2020):

- Brushes - Delivers power from the contacts to the armature through the commutator

- Contacts - Brings power from the controller to the brushes

- Commutator - Delivers power to the appropriate set of windings as the armature rotates

- Windings - Converts electricity to a magnetic field that drives the axle

- Axle - Transfers the mechanical power of the motor to the user application

- Magnets - Provide a magnetic field for the windings to attract and repel

- Bushing - Minimizes friction for the axle

- Can - Provides a mechanical casing for the motor
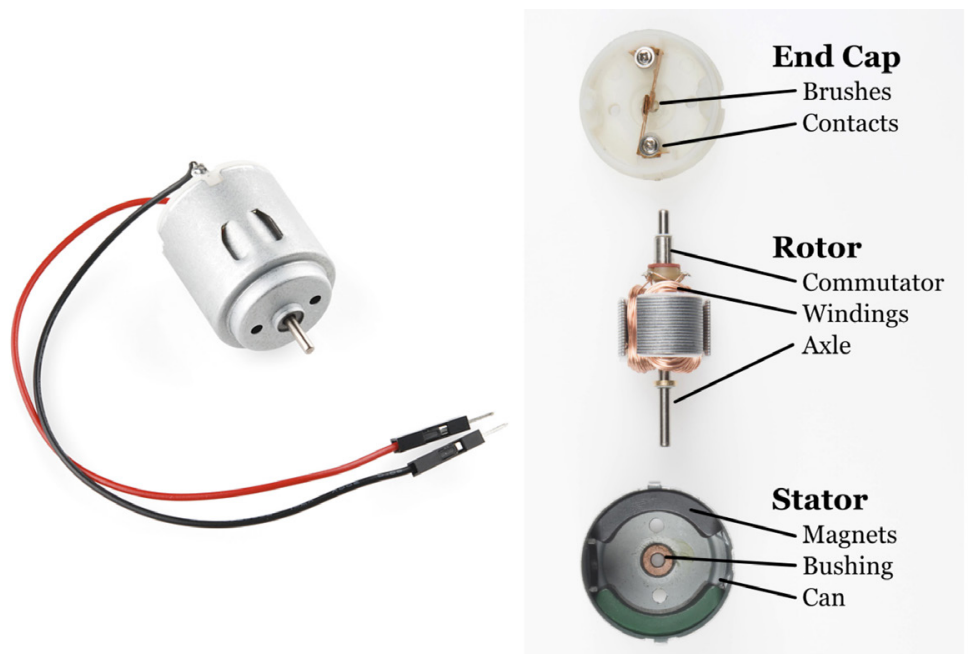

Figure 2 Components of small (hobby) DC motor. Less reliable components of the motor are marked with an asterisk * (Sparkfun, 2020). 
These kinds of motors are simple to control, have an excellent torque at low speed and are inexpensive. On the other hand, the brushes can wear out over time and are limited in speed due to brush heating. For the purpose of experimental testing, these disadvantages are really interesting as an accelerated test can lead to degradation and fault in these two components (windings and contacts). These motors exhibit a particularly short useful life (from 30 minutes to 6 hours) when operating out of nominal conditions, which make them very interesting for testing different signal processing algorithms and introduce students and re-searchers into signal processing, fault detection and predictive maintenance.

For the purpose of experimentation, a small DC motor with the following characteristics has been chosen as the subject of different tests:

- Reference: Motor DC RS PRO (RS-Amidata reference 238-9692)

- Voltage supply: 1.5 - $3 \mathrm{~V} \mathrm{dc}$

- Maximum Output Torque: $13 \mathrm{~g} * \mathrm{~cm}$

- Output Speed: 6250 - 12200 rpm $(104.16 \mathrm{~Hz}-203.33 \mathrm{~Hz})$

- Current Rating: $1.04 \mathrm{~A}$

- Power Rating: $2.51 \mathrm{~W}$

- Shaft Diameter: $2 \mathrm{~mm}$

- Dimensions: 21 (Dia.) x $21 \mathrm{~mm}$

- Weight: $20 \mathrm{~g}$

Following the four fundamental stages of predictive maintenance approach shown earlier, the "Reliability analysis" showed to us that those machine components more susceptible to failure are the contacts and the windings. In a real-life application, we should have an historical set of different failures of same type of DC motors and assess such condition. Next stage is the "Signals selection and measurement" selection to detect wear or faults in contacts and windings. There are different alternatives, but we can say that due to the electrical problems that these components can cause we have to measure the current consumption and supply voltage. In addition to that, the measurement of the temperature and vibration are good candidates to assess the condition too (Wahab et al., 2019; Iorgulescu, M. et al, 2012).

Bellow you can see the experimental setup (Figure 3) used for the measurement of the different signals for the DC motor tested. It is also shown a rubber rotor with two blades used for creating a minimal load on the motor.

Table 1 shows the data acquisition modules together with the sensors used and their sensitivity.

Table 1 list of measurements, sensors and data acquisition modules.

\begin{tabular}{lccc}
\hline \multicolumn{1}{c}{ Measurement } & Sensor & Sensitivity & $\begin{array}{c}\text { Data acquisition } \\
\text { module (channel) }\end{array}$ \\
\hline DC motor vibration & Accelerometer PCB 352 C65 & $98 \mathrm{mV} / \mathrm{g}$ & NI9234 - ai0 \\
\hline DC motor current consumption & Shunt resistor 0,10hm 5W & $10 \mathrm{~V} / \mathrm{A}$ & NI9215 - ai1 \\
\hline DC motor supply voltage & Voltage input & $1 \mathrm{~V} / \mathrm{V}$ & NI9215 - ai0 \\
\hline DC motor external temperature & $\mathrm{J}$ thermocouple & $0-350^{\circ} \mathrm{C}$ & NI9211 - ai0 \\
\hline Ambient temperature & $\mathrm{J}$ thermocouple & $0-350^{\circ} \mathrm{C}$ & NI9211 - ai1 \\
\hline
\end{tabular}

Anibal Reñones and Marta Galende F.A.I.R. open dataset of brushed DC motor faults for testing of $\mathrm{Al}$ algorithms
ADCAIJ: Advances in Distributed Computing and Artificial Intelligence Journal Regular Issue, Vol. 9 N. 4 (2020), 83-94 eISSN: 2255-2863 - https://adcaij.usal.es Ediciones Universidad de Salamanca - CC BY-NC-ND 


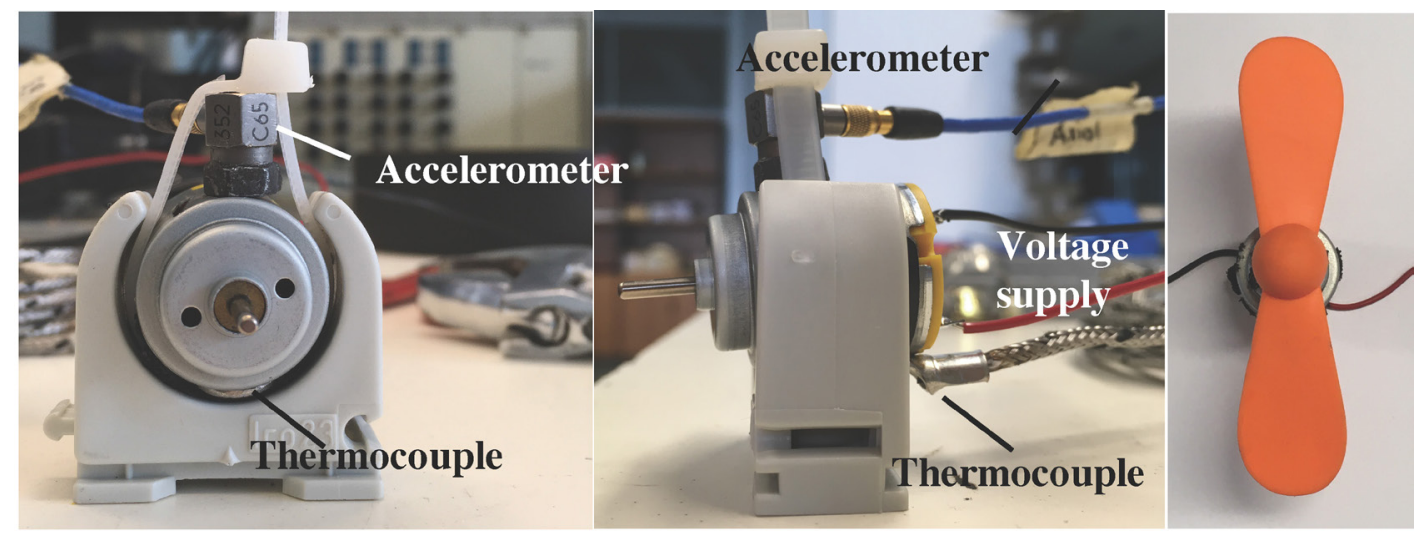

Figure 3 DC motor tested with accelerometer, thermocouple sensors installed and rubber rotor with two blades.

A data acquisition system based on National instruments modules mounted on an USB chassis and a custom software let to sample continuously all the measurements for later analysis. The sample rate was set at $51200 \mathrm{~Hz}$ and the total length of each capture was 5 seconds.

\section{Results}

The DC motor has been tested according the following steps:

- (I) Initial warming up at 3V (8000 rpm) during 15 minutes.

- (II) Increase of power supply to 5V (10.000rpm) where the motor shows firsts signs of wear.

- (III) Reduction again to $3 \mathrm{~V}$ of supply to comparison of signals with warming up stage I.

- (IV) Final test increasing again to $5 \mathrm{~V}$ to finalize stress test.

Bellow it is presented different figures showing the evolution of the measured variables where the four phases of experimentation is clearly distinguished. In phase I and III the consumption of the motor is about 1,5 A where the consumption of stressed phases II and IV raises to 2,5 A approximately. With respect the speed of the motor, phase I shows a constant speed (around $8000 \mathrm{rpm}$ ) and the res of phases, especially II and IV shows a non-constant speed due to the accelerated wear.

Anibal Reñones and Marta Galende F.A.I.R. open dataset of brushed DC motor faults for testing of $\mathrm{Al}$ algorithms
ADCAIJ: Advances in Distributed Computing and Artificial Intelligence Journal Regular Issue, Vol. 9 N. 4 (2020), 83-94 eISSN: 2255-2863 - https://adcaij.usal.es Ediciones Universidad de Salamanca - CC BY-NC-ND 


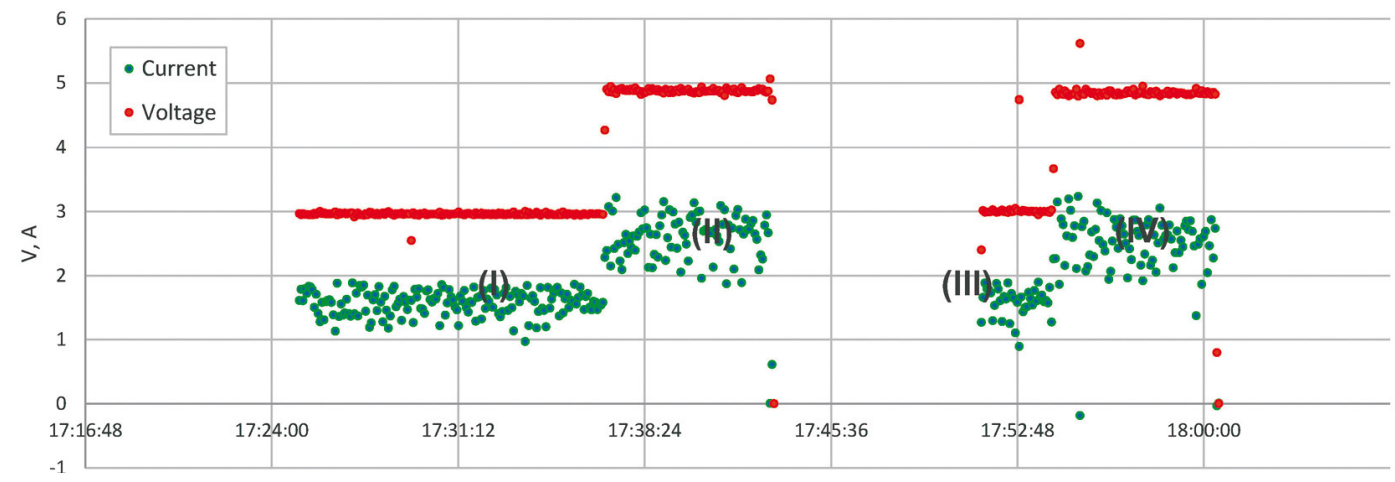

Figure 4 Evolution of voltage and current during the 4 phases of experimentation.

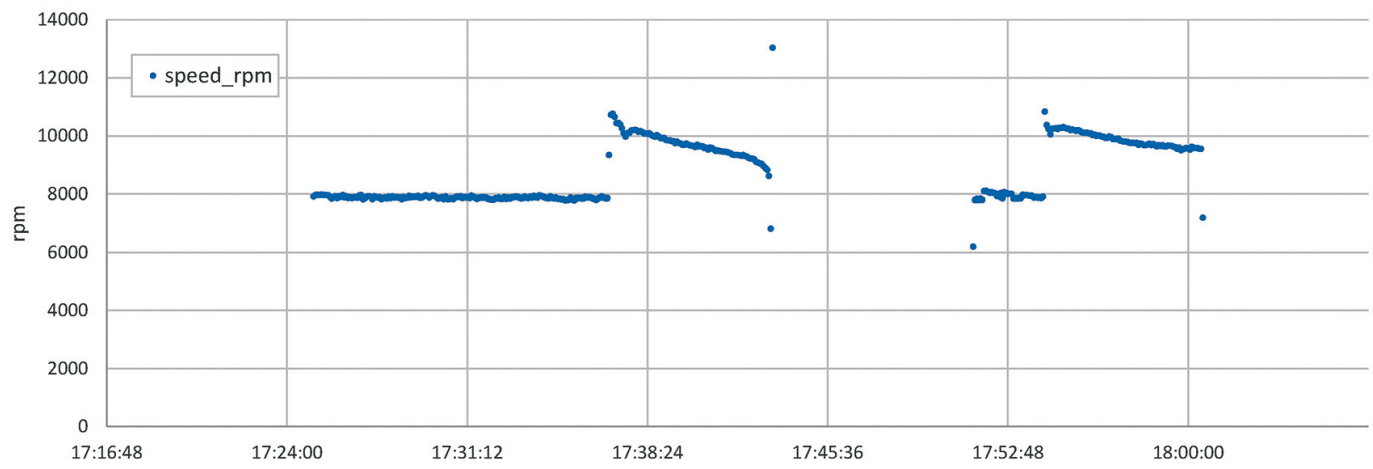

Figure 5 Evolution of motor speed during experimentation.

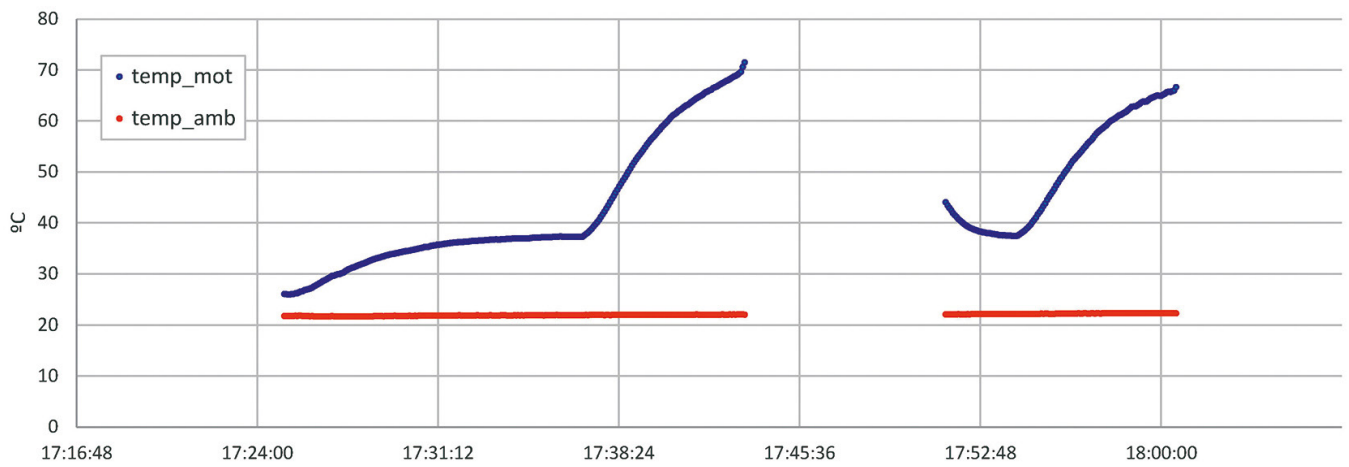

Figure 6 Evolution of motor temperature and ambient temperature during experimentation.

Anibal Reñones and Marta Galende

F.A.I.R. open dataset of brushed DC motor faults for testing of $\mathrm{Al}$ algorithms
ADCAIJ: Advances in Distributed Computing and Artificial Intelligence Journal Regular Issue, Vol. 9 N. 4 (2020), 83-94 eISSN: 2255-2863 - https://adcaij.usal.es Ediciones Universidad de Salamanca - CC BY-NC-ND 
During the experimentation the vibration has been also recorded an analyzed from the point of view the frequency content of the signal. In Figure 7 it is presented the frequency spectrum after 5 minutes of running. The speed of the motor is $131 \mathrm{~Hz}(7860 \mathrm{rpm})$ and the vibration peak at that frequency is clearly visible. In addition to that, the multiples of that frequency are also seen in the spectrum with the $10^{\text {th }}$ multiple (10X in Figure 7 ) as the highest one.

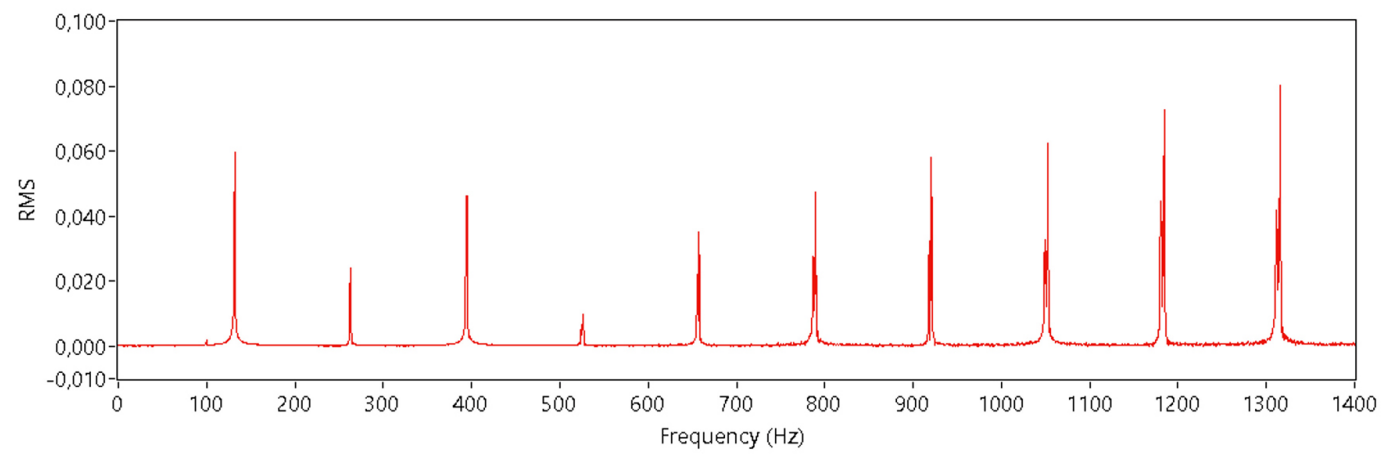

Figure 7 Vibration spectrum (from 0 to $1400 \mathrm{~Hz}$ ) after 5 minutes of running time.

The vibration analysis applied to predictive maintenance of rotating machines is based on the monitoring evolution of specific frequency peaks associated to possible problems and mechanical components of the machine under surveillance. With this idea in mind, the vibration recorded is then analyzed and the RMS content of each frequency peak is calculated. Figure 8 shows the evolution of the $1^{\text {st }}$ three peaks (1X, 2X and 3X in Figure 7) of the rotating frequency during the whole experiment. The figure contains both linear and logarithmic scale to distinguish the lower values of the vibration belonging to the three harmonics. These are the values of the vibration when the motor rotates in its nominal regime $(3 \mathrm{~V}, 8000 \mathrm{rpm})$. When the supply voltage increases above nominal conditions the vibration increases abruptly (around 50 times).

It is clearly seen that after initial $2^{\text {nd }}$ phase the vibration harmonics of the phase III compared with the vibration harmonics of phase I is different due to the impact inside the motor of the phase II where the motor is subjected to higher power supply $(5 \mathrm{~V})$ than maximum allowed by design $(3 \mathrm{~V})$.

In the figure bellow, it is compared the status of the commutators after the end of phase IV. The wear of the three commutators is clear and it is nearly close to exhibit a short circuit among them. It is worth to say that in both cases (worn and new motor) the resistance of the windings is the same (around $1,05 \mathrm{ohm}$ ). We can conclude that the accelerated experimentation had its main impact in the fast wear of the commutators.

Anibal Reñones and Marta Galende F.A.I.R. open dataset of brushed DC motor faults for testing of $\mathrm{Al}$ algorithms
ADCAIJ: Advances in Distributed Computing and Artificial Intelligence Journal Regular Issue, Vol. 9 N. 4 (2020), 83-94 eISSN: 2255-2863 - https://adcaij.usal.es Ediciones Universidad de Salamanca - CC BY-NC-ND 


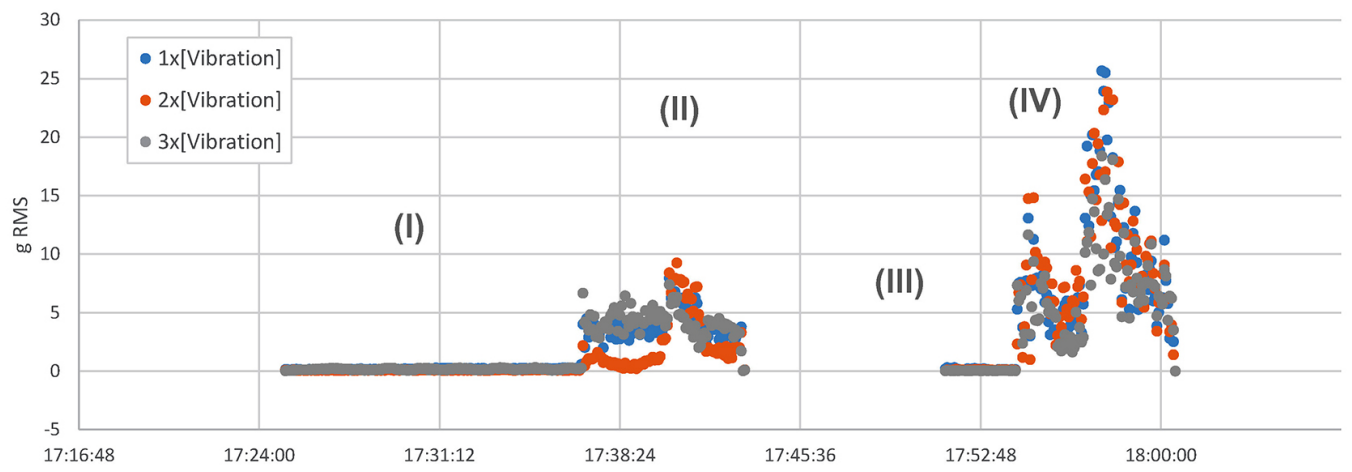

(a)

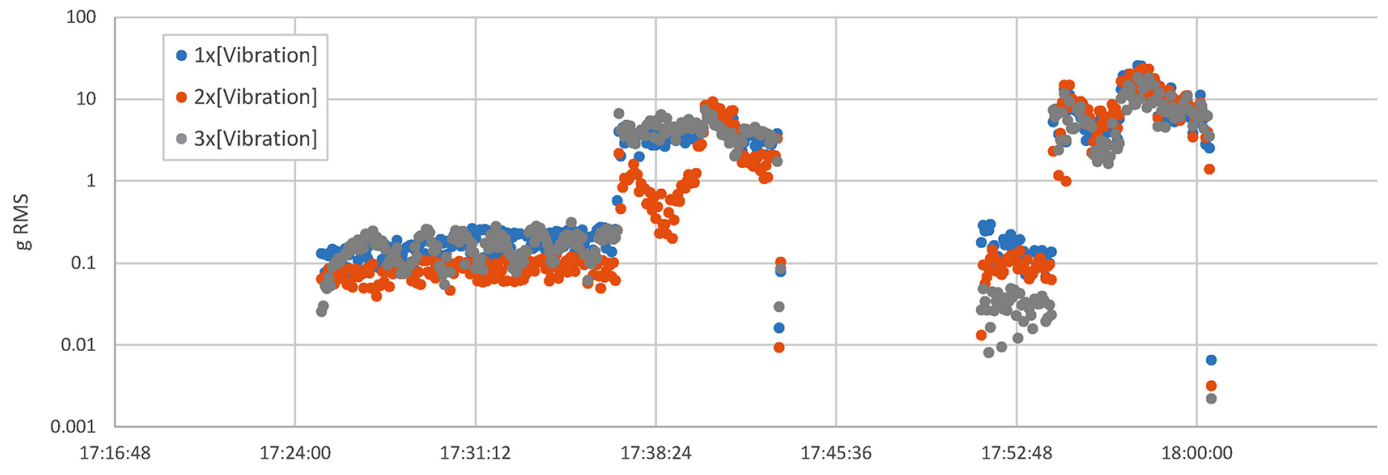

(b)

Figure 8 Evolution of the first three harmonics of the vibration during the experimentation in linear (a) and logarithmic scale (b).

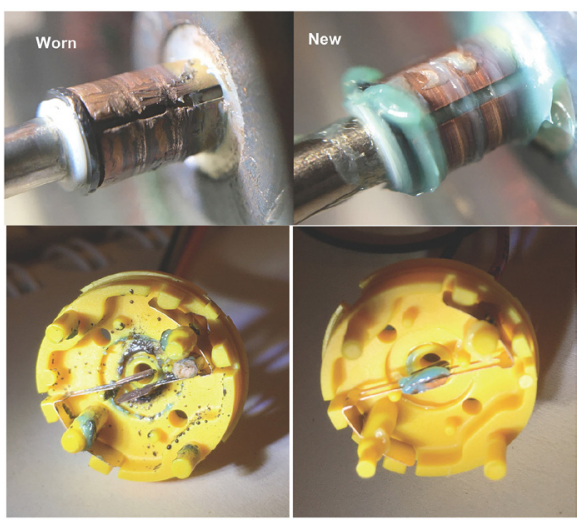

Figure 9 Comparison of commutators (1 st row) and brushes (2nd row) of worn (left) and new (left) DC motors.

Anibal Reñones and Marta Galende

F.A.I.R. open dataset of brushed DC motor faults for testing of $\mathrm{Al}$ algorithms
ADCAIJ: Advances in Distributed Computing and Artificial Intelligence Journal Regular Issue, Vol. 9 N. 4 (2020), 83-94 eISSN: 2255-2863 - https://adcaij.usal.es Ediciones Universidad de Salamanca - CC BY-NC-ND 


\section{Conclusions}

The work presented here shows a lab test done with a DC motor to accelerate wear of the commutators with the idea of generating an open dataset useful for introducing students and researchers into signal processing, fault detection and predictive maintenance. The analysis of the different variables measured (supply voltage, current, temperature and vibration) shows the evolution of the accelerated wear of less reliable component, that is, the commutators that provide the supply voltage to the windings of the DC motor. Among the different variables measured, vibration is clearly the more appropriate to detect, follow and predict the evolution of such fault (wear of the commutators). A signal processing appropriate to detect the rotating speed and then able to calculate the vibration at the rotating frequency and its multiples, can be seen as the more appropriate technique for predictive maintenance. With the idea of making available to the AI community both the signal processing outputs and the original recorded raw signals (vibration, current and voltage) the authors have created a dataset available to the research and educational community so they can test different techniques and compare results.

In future works the authors would like to create other testing conditions to generate wear or faults in other components of the DC motor like for example in the windings.

The dataset has been made openly available through the AI4EU platform at this link: https://www. ai4eu.eu/resource/opendcmotor and through the Zenodo open data repository in this other link: https:// doi.org/10.5281/zenodo.4314249.

\section{Acknowledgments}

The work presented here has been done thanks to the SMART-FACTORY project funded by the European Regional Development Fund (ERDF) of the European Union and the "Junta de Castilla y León" regional government (ref: CCTT1/17/VA/0003).

The authors wish to thank Mario de la Rosa Noriega for his help with the translation and conversion of test experiments raw data file to the open HDF5 format (HDF Group, 2020).

\section{References}

Bevilacqua, M. and Braglia, M. (2000), "The analytic hierarchy process applied to maintenance strategy selection", Reliability Engineering and System Safety, Vol. 70 No. 1, pp. 71-83.

European Commission, 2018. "Turning FAIR into reality", Directorate General for Research and Innovation, ISBN 978-92-79-96546-3. doi: 10.2777/1524

European Commission, 2020. European data strategy: Making the EU a role model for a society empowered by data, https://ec.europa.eu/info/strategy/priorities-2019-2024/europe-fit-digital-age/ european-data-strategy_en, accessed November 28, 2020.

European Commission, 2020. European Data Governance, https://ec.europa.eu/digital-single-market/en/ european-data-governance, accessed November 28, 2020.

European Commission, 2020. Open Research Europe - The European Commission open access publishing platform, https://open-research-europe.ec.europa.eu/about, accessed November 28, 2020.

Anibal Reñones and Marta Galende F.A.I.R. open dataset of brushed DC motor faults for testing of $\mathrm{Al}$ algorithms
ADCAIJ: Advances in Distributed Computing and Artificial Intelligence Journal Regular Issue, Vol. 9 N. 4 (2020), 83-94 eISSN: 2255-2863 - https://adcaij.usal.es Ediciones Universidad de Salamanca - CC BY-NC-ND 
European Commission, 2020. Open Research Europe - Data guidelines, https://open-research-europe. ec.europa.eu/for-authors/data-guidelines, accessed November 28, 2020.

Fang Lin Luo, Hong Ye, Muhammad Rashid, Chapter 11 - Energy Factor Application in AC and DC Motor Drives, Editor(s): Fang Lin Luo, Hong Ye, Muhammad Rashid, Digital Power Electronics and Applications, Academic Press, 2005, Pages 314-347, ISBN 9780120887576, https://doi.org/10.1016/ B978-012088757-6/50012-X.

Herman, Stephen. Industrial Motor Control. 6th ed. Delmar, Cengage Learning, 2010.

HDF Group, 2020. Introduction to HDF5, https://portal.hdfgroup.org/display/HDF5/Introduction+to+ HDF5+--+PDF, accessed December 10, 2020.

Iorgulescu, Mariana \& Beloiu, Robert. (2012). Study of DC motor diagnosis based on the vibration spectrum and current analysis. 2012 International Conference on Applied and Theoretical Electricity, ICATE 2012 - Proceedings. 1-4. 10.1109/ICATE.2012.6403430.

IoT Analytics, Predictive Maintenance: Market Report 2017-2022, marzo 2017.

Liu, Y., Guo, L., Wang, Q., An, G., Guo, M., \& Lian, H. (2010). Application to induction motor faults diagnosis of the amplitude recovery method combined with FFT. Mechanical Systems and Signal Processing, Vol. 24, No. 8, pp. 2961-2971. doi:10.1016/j.ymssp.2010.03.008.

Nazmus Sakib, Thorsten Wuest, Challenges and Opportunities of Condition-based Predictive Maintenance: A Review, Procedia CIRP, Volume 78, 2018, Pages 267-272, ISSN 2212-8271, https:// doi.org/10.1016/j.procir.2018.08.318.

Patton RJ, Chen J, Nielsen SB. Model-based methods for fault diagnosis: some guide-lines. Transactions of the Institute of Measurement and Control. 1995;17(2):73-83. doi:10.1177/014233129501700203

Wilkinson, M., Dumontier, M., Aalbersberg, I. et al. The FAIR Guiding Principles for scientific data management and stewardship. Sci Data 3, 160018 (2016). https://doi.org/10.1038/sdata.2016.18

Sparkfun, 2020. Motors and Selecting the Right One, https://learn.sparkfun.com/tutorials/motors-andselecting-the-right-one/all, accessed November 28, 2020.

Venkatraman Narayan, (2012),'Business performance and maintenance", Journal of Quality in Maintenance Engineering, Vol. 18 Iss 2 pp. 183-195.

Wahab, Abbas \& Abdullah, N \& Rasid, Mohd Azri Hizami. (2019). Commutator fault detection of brushed DC motor using thermal assessment. IOP Conference Series: Materials Science and Engineering. 469. 012057. 10.1088/1757-899X/469/1/012057.

Yanqing Duan et al. Artificial intelligence for decision making in the era of Big Data - evolution, challenges and research agenda, International Journal of Information Management, Volume 48, 2019, Pages 63-71, ISSN 0268-4012, https://doi.org/10.1016/j.ijinfomgt.2019.01.021.

Wapcaplet, DC motor schematic view. https://en.wikipedia.org/wiki/Image:Electric_motor_cycle_2.png, accessed November 28, 2006.

Anibal Reñones and Marta Galende F.A.I.R. open dataset of brushed DC motor faults for testing of $\mathrm{Al}$ algorithms
ADCAIJ: Advances in Distributed Computing and Artificial Intelligence Journal Regular Issue, Vol. 9 N. 4 (2020), 83-94 eISSN: 2255-2863 - https://adcaij.usal.es Ediciones Universidad de Salamanca - CC BY-NC-ND 